\title{
A história da filosofia no discurso de John Dewey sobre a moral
}

\author{
Paulo Fernando Aleixo da Cruz ${ }^{*}$ \\ Marcus Vinicius da Cunha**
}

\section{Resumo}

Este artigo segue diretrizes teóricas e metodológicas oriundas de Chaïm Perelman e Stephen Toulmin, cujos fundamentos se encontram no movimento contemporâneo de revisão da filosofia de Aristóteles. Seu objetivo consiste em fazer a análise retórica do ensaio "Intelligence and Morals" ["Inteligência e Moral"] de John Dewey, publicado em 1908, no qual o autor defende a tese de que desde o Renascimento a moral se tornou desvinculada de fins transcendentais, sendo, então, baseada na inteligência. $\mathrm{O}$ exame do ensaio revela o uso da estratégia discursiva denominada recurso à origem, a qual consiste em elaborar uma narrativa genealógica sobre história da filosofia com o intuito de sustentar a tese do autor. O trabalho sugere que essa forma de argumentar é frequente na obra de Dewey, sendo observada também no livro Democracy and education [Democracia e educação], no qual o filósofo discorre sobre a história da filosofia para evidenciar que a reflexão filosófica em educação emerge de problemáticas sociais.

Palavras-chave: Dewey, John. Retórica. Filosofia e Educação.

\footnotetext{
* Graduado em Pedagogia pela Faculdade de Filosofia, Ciências e Letras de Ribeirão Preto da Universidade de São Paulo (USP).

*** Doutor em Educação pela Universidade de São Paulo (USP). Professor do Curso de Pedagogia e da Pós-Graduação em Educação na Universidade de São Paulo (USP) e colaborador do Programa de Pós-graduação em Educação Escolar da Universidade Estadual Paulista Araraquara (UNESP).
} 


\section{Introdução}

O presente artigo é vinculado a uma linha de investigação dedicada a compreender o discurso filosófico e educacional de John Dewey (1859-1952), autor norte-americano, cuja influência no campo da educação percorreu todo o século XX e permanece ainda na atualidade. A metodologia empregada para alcançar esse objetivo decorre dos estudos de Chaïm Perelman, formulados especialmente no Tratado da Argumentação (PERELMAN; OLBRECHTS-TYTECA, 2002), obra cuja proposição teórica e metodológica é associada ao movimento contemporâneo de revisão do pensamento de Aristóteles, caracterizado pela destacada ênfase nos Tópicos e na Retórica.

Uma das metas da análise retórica, tal qual praticamos em nossas investigações, consiste em elucidar as estratégias argumentativas contidas em textos de Dewey, considerando que toda manifestação discursiva envolve três componentes: um orador, o autor que utiliza argumentos com a intenção de mobilizar as disposições emocionais e intelectuais de outrem; o texto impresso, que contém o discurso, ou seja, a trama argumentativa que visa realizar o intento do orador; e os leitores, a quem denominamos audiência, identificados como aqueles a quem se pretende persuadir por meio da argumentação (CUNHA, 2010).

O levantamento das estratégias argumentativas dos discursos em exame é facilitado por um procedimento que deriva dos trabalhos de Stephen Toulmin, filósofo vinculado ao movimento revisionista da obra aristotélica, a exemplo de Perelman. Em Os usos do argumento, Toulmin (2001) propõe um novo formato (layout) para a apresentação dos enunciados que compõem os silogismos: uma das premissas opera como um Dado a partir do qual o orador formula a Conclusão de seu raciocínio; a passagem do Dado à Conclusão é viabilizada por uma premissa que recebe o nome de Garantia, pois sem ela a referida passagem não teria sustentação. Pode-se ilustrar essa proposta com o seguinte raciocínio: a transição do Dado "Sócrates é homem" à Conclusão "Sócrates é mortal" só se torna aceitável mediante a Garantia "Todos os homens são mortais".

O autor qualifica a Garantia como um enunciado de caráter hipotético, de natureza teórica, com o qual podemos ou não concordar. Na ilustração apresentada acima, a aceitação praticamente unânime de "Todos os homens são mortais" decorre de que todos os homens que nasceram até hoje morreram, e é possível citar um número bastante grande de casos para argumentar - indutivamente, é claro - em favor desta afirmação. No vocabulário de Toulmin (2001), a argumentação que sustenta a Garantia é denominada Apoio. 
Graficamente, temos no Quadro 1 o seguinte layout.

Quadro 1 - O layout proposto por Toulmin

(Dado) Sócrates é homem $\rightarrow$ (Conclusão) Sócrates é mortal
(Garantia) Todos os homens são mortais
(Apoio) Todos os homens que nasceram até hoje estão mortos

Fonte: Adaptado de Toulmin (2001).

Como se pode notar, o raciocínio expresso no enunciado denominado Apoio é de fundamental importância para conferir credibilidade ao discurso, o que indica a relevância de se compreender as estratégias argumentativas que compõem afirmações dessa natureza, cujo objetivo consiste em firmar a Garantia.

O layout de Toulmin (2001) também permite conhecer eventuais argumentos destinados a contrariar a tese do orador. No quadro 1, uma Refutação ao Apoio "Todos os homens que nasceram até hoje estão mortos" poderia vir da manifestação de uma audiência insatisfeita com a qualidade ou a quantidade de casos apresentados, afirmando, digamos, que não foi possível observar realmente todos os homens, particularmente os que ainda estão vivos, de modo que a afirmação da mortalidade dos seres humanos não pode ser feita em sentido universal.

A proposta do autor chama a atenção para o caráter dialético de todo discurso que se dispõe a examinar e propor soluções para determinado problema, em qualquer campo do conhecimento, em especial nas ciências humanas. Esse caráter torna-se evidente quando observamos que os autores de textos propositivos usualmente tomam precauções ao apresentarem seus argumentos, como se estivessem envolvidos em um debate público; os discursos pretensamente persuasivos costumam trazer contra-argumentos preventivos à interposição de ressalva às ideias defendidas.

É assim porque os argumentos concernentes a assuntos humanos e sociais não pertencem ao estreito campo do necessário, mas ao âmbito da contingência. Por isso, as suas conclusões devem 
sempre conter expressões modais que indiquem essa característica. Na ilustração examinada, levando em conta a possibilidade de uma objeção, o enunciado conclusivo do raciocínio deveria ser "Sócrates, provavelmente, é mortal".

É importante salientar que essa abordagem metodológica não almeja emitir julgamentos valorativos acerca de autores, como se fosse possível revelar o grau de verdade contido em seus discursos, mas somente esclarecer os recursos que tornam efetiva a argumentação apresentada. A análise retórica pretende compreender as estratégias discursivas postas em ação quando um autor comunica determinadas teses com o propósito de persuadir determinada audiência, para que as ideias defendidas sejam passíveis de aceitação e, na medida do possível, para que resultem em ações concretas. Na área da educação, esse empreendimento é de fundamental importância para que a audiência - os leitores dos textos educacionais - possa deliberar com clareza a respeito das propostas que lhes são apresentadas e, consequentemente, agir em consonância com elas.

Tendo por base outros estudos concernentes ao mesmo tema, o presente trabalho focalizará o ensaio "Intelligence and morals", de John Dewey (1997a), publicado em 1908, quando o autor encontrava-se trabalhando na Universidade de Colúmbia, em Nova York. Seguindo as diretrizes da análise retórica, apresentaremos Dewey como orador que busca veicular uma tese pertencente aos campos da filosofia e da educação, para em seguida examinarmos as características de sua audiência naquele momento. Por fim, focalizaremos as articulações do texto com o intuito de compreender sua principal estratégia retórica, do recurso à história da filosofia. Para concluir, teceremos sobre algumas considerações sobre o uso dessa estratégia, a qual nos parece típica do discurso deweyano, tanto sobre a filosofia quanto sobre a educação.

\section{O orador e sua tese}

John Dewey concluiu os estudos universitários em 1879, em Vermont, seu estado natal, onde conheceu as ideias de Thomas H. Huxley sobre as teorias de Darwin, fato que exerceu forte influência sobre a sua visão de mundo (AMARAL, 1990). Em 1884, doutorou-se com uma tese sobre Kant na Universidade Johns Hopkins; ali manteve contato com G. S. Morris, que apresentou a ele a filosofia de Hegel, cujas teses marcaram profundamente as suas ideias naquele momento (GARRISON, 2006). Na Universidade de Michigan, onde começou a trabalhar em 1884, conheceu o Pragmatismo, corrente de pensamento fundada por William James e Charles S. Pierce, à qual aderiu definitivamente. Foi também 
naquela instituição que manteve contato com outro pragmatista célebre, George H. Mead, autor de concepções sobre o cérebro e a mente que o levaram a compreender a íntima relação entre organismo e ambiente (CUNHA, 2011).

$\mathrm{Na}$ Universidade de Chicago, para onde se transferiu em 1894, Dewey organizou e dirigiu uma escola elementar dedicada a colocar em prática as suas teses filosóficas no campo da educação (MOREIRA 2002). Valdemarin (2010) considera que a experiência da Escola Laboratório, como ficou conhecida aquela instituição de ensino, deu fundamento às propostas educacionais deweyanas que se encontram, por exemplo, nos ensaios “A criança e o programa escolar” (DEWEY, 1978a) e "Interesse e esforço" (DEWEY, 1978b) e nos livros Como pensamos (DEWEY, 1953) e Democracia e educação (DEWEY, 1959).

Esse último livro exprime as concepções mais bem acabadas da teorização deweyana em prol de uma nova educação, que prevê não somente a revisão de objetivos e métodos de ensino, em respeito à individualidade de cada educando, mas fundamentalmente uma nova concepção de experiência, que é assim definida:

Em seu aspecto ativo, a experiência é tentativa - significação que se torna manifesta nos termos experimento, experimentação que lhe são associados. No aspecto passivo, ela é sofrimento, passar por alguma coisa. Quando experimentamos alguma coisa, agimos sobre ela, fazemos alguma coisa com ela; em seguida sofremos ou sentimos as consequências. Fazemos alguma coisa ao objeto da experiência, e em seguida ele nos faz em troca alguma coisa: essa é a combinação específica de que falamos. A conexão dessas duas fases da experiência mede o fruto ou o valor da mesma. A simples atividade não constitui experiência. (DEWEY, 1959, p. 152, grifos do autor).

Em obra posterior, Experiência e educação, Dewey (1971, p. 25-26) acrescenta que "toda experiência modifica quem a faz e por ela passa, e a modificação afeta, quer o queiramos ou não, a qualidade das experiências subsequentes". Ampliando o tradicional conceito de "hábito", o autor (DEWEY, 1971, p. 26) refere-se à experiência como algo que "envolve a formação de atitudes tanto emocionais, quanto intelectuais; envolve toda nossa sensibilidade e modos de receber e responder a todas as condições que defrontamos na vida".

Sua crítica à educação contemporânea consiste na observação de que os alunos são instruídos “como se adquirissem conhecimentos na qualidade de puros expectadores, de espíritos que absorvem os conhecimentos pela energia direta da inteligência", pois estamos habituados a "separar a coisa que se chama espírito ou consciência, dos órgãos físicos da atividade", concebendo a "consciência como 
faculdade puramente intelectual e cognitiva, e aqueles últimos como fatores físicos intrusos e sem importância" (DEWEY, 1959, p. 153).

As proposições educacionais deweyanas são apoiadas em uma crítica à filosofia tradicional, assim denominada por buscar fundamento para a existência humana em um poder que transcenda a experiência, que é vista, portanto, como eivada de erros, defeituosa. A filosofia criticada por Dewey é aquela que supõe haver algo acima da experiência comum, um plano puramente racional e conceitual capaz de proporcionar certeza inabalável à vida. Essa tradição de pensamento remonta à Grécia Clássica, quando se concebeu que o homem e suas instituições deviam submeter-se à ordem da natureza, um ordenamento fixo e imutável onde supostamente se situa a razão de ser de toda existência (CUNHA, 2011).

O Pragmatismo de James, Peirce e Mead, aliado ao Evolucionismo de Darwin, levou Dewey a perceber que a resposta para as indagações acerca da existência devia ser buscada na interação do organismo com o ambiente circundante, processo em que se constituem a linguagem e a mente, únicos instrumentos disponíveis para efetivar o duplo processo que define a vida: a adaptação do homem ao meio e, ao mesmo tempo, a ação humana voltada a transformar o meio para favorecer a vida (CUNHA, 2011).

As proposições educacionais e as concepções epistemológicas de Dewey são, portanto, dois campos estreitamente vinculados. A ideia de posicionar a experiência do aluno - a interação do indivíduo com o mundo - no centro do processo de ensino requer a superação de determinado molde intelectual que, delineado pela tradição filosófica, constitui uma cultura de pensamento fortemente arraigada no homem contemporâneo.

\section{A audiência, um desafio para o Orador}

Dewey saiu de Chicago em 1904, ingressando em seguida na Universidade de Columbia ${ }^{1}$. Seu nome, então, já era bastante conhecido e respeitado nos meios acadêmicos, tanto por educadores quanto por filósofos, mas o ambiente intelectual naquela instituição não era dominado pelo Pragmatismo, como atesta Hahn (2008), razão pela qual os seus primeiros trabalhos produzidos naquela época foram dedicados a divulgar e esclarecer as suas ideias utilizando um vocabulário menos técnico. Nos termos da análise retórica, podemos dizer que Dewey viu-se diante do desafio de encontrar estratégias 
argumentativas adequadas para interagir com uma audiência nova, não inteiramente habituada às suas teses.

A análise retórica de dois importantes ensaios produzidos por Dewey naquele período - "The philosophical work of Herbert Spencer" (DEWEY, 1997c) e "The influence of darwinism on philosophy" (DEWEY, 1997b) - revelam algumas características do discurso por ele articulado para enfrentar tal desafio: Dewey procura situar o Pragmatismo no centro da filosofia contemporânea, como legítimo representante do que havia de mais avançado na história do pensamento ocidental (CUNHA; CARVALHO, 2011); sua argumentação pode ser descrita pela metáfora percurso indeterminado, a qual, privilegiando raciocínios pautados na ação e reflexão individuais, sugere uma forma de educação baseada no intercâmbio afetivo entre educadores e educandos, em oposição à ênfase na quantificação das práticas escolares (CARVALHO; SILVA; CUNHA; 2014).

O ensaio "Intelligence and morals" (DEWEY, 1997a) também reflete o esforço de Dewey para enfrentar o referido desafio de apresentar as teses do Pragmatismo, sustentáculo de suas propostas educacionais, a uma audiência nova. Desse modo, trata-se de discutir as teorias da moral com o intuito de firmar uma perspectiva inovadora, distanciada das formulações tradicionais até então hegemônicas no campo da filosofia.

O tema da moral é relevante por ocupar o centro da tradição filosófica a ser combatida em prol de uma nova abordagem educacional. Em "Intelligence and morals", Dewey (1997a, p. 70-71) procura mostrar que essa tradição estabeleceu um "objetivo final” a ser buscado pelo homem, como também a crença em uma "única força motivadora" e uma "faculdade distinta e infalível” capazes de oferecer respostas necessárias para moldar a existência. Em oposição, sustenta a tese de que uma nova concepção moral permitirá "acelerar a investigação acerca da diversidade de valores específicos da experiência", aliviando os homens da "responsabilidade por aquilo que não podem fazer" e os chamando à responsabilidade por aquilo que não fizerem de modo apropriado por causa de sua “incapacidade para pensar de maneira exata e cuidadosa” (DEWEY, 1997a, p. 71).

Segundo o autor (1997a, p. 71), a crença em "valores absolutos" deve ser superada para que se torne viável a "participação de todos os homens nos valores naturais e sociais". Assim, atribuindo à moral um caráter experimental, sem o amparo de valores supremos e inquestionáveis, Dewey pretende firmar a ideia de que os problemas humanos devem ser examinados pela inteligência, contrariamente ao que se apresenta na tradição filosófica² ${ }^{2}$. 
Para tornar plausível essa tese, Dewey (1997a) opta por elaborar uma narrativa que acompanha o desenvolvimento do conceito de inteligência em suas relações com a moral, desde os primórdios da reflexão filosófica até o momento atual, isto é, o momento em que o tema é comunicado àquela audiência específica, determinada pelo contexto educacional e filosófico da primeira década do século XX.

\section{Nos primórdios, a inteligência}

Em "Intelligence and morals", o primeiro passo argumentativo dado por Dewey (1997a) consiste em identificar a origem da tradição filosófica por ele combatida. Essa origem é identificada nos gregos antigos, que, ao considerarem que o objetivo da vida é a busca do bem, deram início à reflexão filosófica colocando a inteligência como elemento central nesse processo. Sendo assim, a moral então vigente deveria substituir os costumes firmados pela tradição, mas a razão, que viria guiar esse empreendimento, continuou vinculada ao passado, mantendo a crença em valores finais e em uma moral única e excludente.

Sócrates assumiu a responsabilidade por trazer a filosofia para a esfera dos problemas concretos da humanidade, mas os seus sucessores optaram por caminhos diferentes, ocasionando o distanciamento entre o pensar filosófico e as condutas humanas (DEWEY, 1997a). Platão concebeu a moral e a filosofia como campos sobrepostos, pois o amor à sabedoria era, para ele, fonte segura para o bem maior. Sua filosofia concebeu que a razão era divina e permanecia ainda adormecida no homem comum, cujas ações eram norteadas somente pelo que provinha dos sentidos.

Aristóteles desenvolveu outro posicionamento, propondo que a racionalidade podia ser alcançada no convívio entre os homens, prática que elevaria todos ao plano da razão. No entanto, ao qualificar o pensamento puro como excelência mais elevada, associada ao divino, exaltou a inteligência em detrimento da "excelência cívica" e da "necessidade social" (DEWEY, 1997a, p. 49). O filósofo de Estagira acreditava que as "distinções de classes de superioridade e inferioridade, como entre homem e mulher, senhor e escravo, pensamento independente e pensamento mecânico" (DEWEY, 1997a, p. 50) tinham justificativa na natureza. Desse modo, afiançou o modo de vida excludente dos gregos, ao conceber o estado como instituição natural, único espaço em que a vida individual poderia alcançar “independência e completude"; fora dele, ou se é "uma fera ou um deus" (DEWEY, 1997a, p. 48). 
Dewey (1997a, p. 55) considera que o pensamento grego deu origem à tradição de submeter o estado e o indivíduo a uma "ordem cósmica", coibindo, assim, o "livre emprego da inteligência humana". Mas a sua herança filosófica não foi responsável pelo "estado de barbárie" que se instalou adiante, na Europa medieval, embora tenha servido de justificativa para tal. No medievo, a filosofia contribuiu para a estagnação das condições práticas, o que acabou fortalecendo os "piores defeitos do bárbaro europeu" (DEWEY, 1997a, p. 52-53). Segundo o autor, essa é a consequência de utilizar a inteligência para converter "circunstâncias flutuantes" em "ideais finais".

Não foi necessária uma teoria moral para iniciar e explicar as segregações, a intolerância e o antagonismo dos "redimidos e condenados" do sistema feudal. Quando os teóricos gregos estabeleceram a distinção entre o racional e o irracional, também associaram a verdade ao bem divino e definiram a condição humana como fraca e corrupta, e, com isso, validaram os antagonismos e a “dominação terrena em prol da excelência eterna” (DEWEY, 1997a, p. 53).

\section{$O$ renascimento da inteligência}

Segundo a narrativa elaborada por Dewey (1997a), os filósofos da era renascentista retomaram o movimento iniciado pelos gregos, provendo, assim, o retorno da inteligência ao campo flutuante das questões concernentes à vida social. $\mathrm{O}$ autor afirma que os renascentistas rejeitaram o isolamento metafísico no exame dos assuntos humanos, permitindo que a "mente livre" contribuísse para desintegrar a "cosmologia" e a "teologia animista" até então vigentes. A liberdade característica daquele período permitiu a separação entre as ciências e a ética; ao abandonar a ideia de "fim moral fixo e estático", a inteligência tornou-se "pré-condição necessária à existência de uma ciência livre e progressista" (DEWEY, 1997a, p. 56). Uma vez emancipadas, as ciências ficaram disponíveis para favorecer a criação e a manutenção dos valores necessários à vida prática.

Dewey (1997a, p. 57) enfatiza que o movimento industrial e comercial característico da modernidade só foi possível porque esteve diretamente associado ao avanço da ciência livre ocorrido naquele momento. Aliada ao desenvolvimento industrial, a emancipação das ciências permitiu que os homens assumissem o "controle das forças naturais", sentindo-se livres para assegurar a todos uma "vida abundante e liberal" (DEWEY, 1997a, p. 58). A mudança moral decorrente de tal conjuntura foi ocasionada, por sua vez, pelas novas relações comerciais, o que se evidenciou quando Adam Smith qualificou a atividade econômica como "fonte móvel” da busca por melhores condições de vida. 
Outra relevante expressão da vida moderna foi o movimento democrático, entendido não apenas como incremento das tendências cientificas e industriais, mas fundamentalmente por seu significado para a coletividade. A fé na democracia só foi viabilizada porque, em decorrência do mesmo processo que constituiu a ciência e a indústria, a inteligência perdeu o caráter de "poder cósmico". A fixidez dos costumes foi substituída pelo "comércio móvel", em consonância com a "dinâmica do progresso social, não com a patologia da ganância privada”, afirma Dewey (1997a, p. 59-60).

O processo de recuperação da inteligência no campo da moral sofreu alguns abalos no século XIX, época em que se verificou certo enfraquecimento do "otimismo complacente" no qual o século anterior havia se apoiado; deu-se, então, um avanço da desconfiança na possibilidade de o homem conquistar o "reino do bem-estar social". Tal pessimismo, no entanto, não solapou inteiramente a ideia de "harmonia social de interesses", segundo a qual, cada indivíduo deve contribuir livremente para aperfeiçoar os poderes da coletividade e, assim, instituir uma "sociedade fraternalmente organizada". O otimismo prevaleceu porque continha uma "contribuição permanente" ao pensamento, ainda que representasse um problema a ser enfrentado (DEWEY, 1997a).

Dewey (1997a) explica que o sistema moral que mais se aproximou dos movimentos científicos, democráticos e industriais daquele período foi o Utilitarismo, que se mostrou, no entanto, insuficiente para atender as necessidades da época. Os utilitaristas que se apropriaram das teses de Adam Smith ignoraram o fato de que o indivíduo só pode contribuir para o bem geral no interior de um estado que garanta a todos iguais oportunidades de participação no "bem comum".

Segundo o autor (1997a, p. 61), a influência de Newton marcou de tal maneira o pensamento moral do século XVIII que "todos os grandes nomes do iluminismo estiveram envolvidos na pesquisa sobre o sistema de investigação científica da moral", com destaque para David Hume e os dois expoentes do utilitarismo, Jeremy Bentham e John Stuart Mill. Os problemas da moral poderiam ter sido postos sob o comando de uma ciência experimental, se não fosse a influência de Kant e seus sucessores, que levaram o pensamento germânico a "preservar as tradições que vinculam a cultura ao passado" (DEWEY, 1997a, p. 63). Kant firmou a razão em um plano distante da natureza e do mundo objetivo; Hegel, por sua vez, tentou "preencher a razão vazia de Kant com conteúdos concretos da história", o que resultou na afirmação de que a "história é a razão, e a razão é a história: o real é o racional e o racional é o real" (DEWEY, 1997a, p. 66).

Na avaliação feita por Dewey (1997a, p. 70), a concepção contrária à fixidez dos fins causou preocupação e insegurança a muitos pensadores do século XIX, pois o declínio da ciência tida como 
“verdadeira e valiosa", então representada pelo domínio das causas finais, significava uma ameaça à própria ciência, como também à moral. Mas o saldo do conturbado movimento de ideias desenvolvido desde a transição da era renascentista para a modernidade foi positivo, uma vez que levou a noção de "processo" a superar a crença em origens e fins inamovíveis; tratou-se uma autêntica transformação que permitiu à inteligência distanciar-se daquela crença, para se firmar como recurso útil às atividades humanas.

\section{A inteligência como valor permanente}

Sustentado na narrativa sobre o avanço das teorias da moral em diversos momentos da história da filosofia, Dewey (1997a, p. 70) conclui ser factível "antecipar uma mudança na atitude dos homens". Uma vez abolidas as ideias de objetivo final e força única motivadora da conduta humana, as quais decretavam a existência de uma "faculdade distinta e infalível" no campo da moral, tornou-se possível "acelerar a investigação acerca da diversidade de valores específicos da experiência" (DEWEY, 1997a, p. 70). Essa mudança - acredita o filósofo - atingirá o modo como a humanidade vê a si mesma, bem como a maneira como os homens encaram as suas próprias ações, as quais serão doravante permeadas por um inédito senso de responsabilidade.

Nessa nova perspectiva que se abre para os problemas da moral, os valores absolutos ficarão em segundo plano, tornando imprescindível a "participação de todos os homens nos valores naturais e sociais" (DEWEY, 1997a, p. 71). Trata-se de um retorno aos princípios socráticos, com a diferença de que existe agora uma série de ferramentas de investigação e teste, assim como significativo acúmulo de conhecimentos, o que viabilizará resolver o problema da participação de todos nas deliberações acerca dos valores norteadores da existência.

Dewey (1997a) considera ainda que o progresso da ciência experimental possibilitará um conhecimento mais assertivo acerca das condições em que se processam as mudanças físicas e sociais, o que, por sua vez, levará a um aumento no grau de controle sobre o intento de "orientar a mudança natural". Estando o homem em condições de direcionar as mudanças futuras, cresce substancialmente a sua responsabilidade nesse processo. Com essa afirmação, o autor conclama sua audiência a posicionar-se perante problemas de ordem moral, pois o referido direcionamento deve visar sempre um "bem maior". 
A capacidade humana é delimitada pelos recursos proporcionados pelo meio e pelas condições próprias do homem, devendo todos esses fatores ser submetidos a uma regulação. Dewey (1997a, p. 74) entende que essa regulação deve ser desenvolvida no âmbito do juízo moral, guiada por "uma exigência inteligente de responsabilidade quanto ao uso dos poderes humanos". Nenhum homem jamais viveu com a "aprovação exclusiva de sua própria consciência”, sendo necessária a concordância dos demais homens. Se a inteligência não for chamada a conduzir esse processo, a lacuna deixada pela antiga moral será automaticamente preenchida "códigos de classe, com as normas de classe, com as aprovações de classe" (DEWEY, 1997a, p. 75).

Para evitar que ocorra a hegemonia de tais códigos e normas e que, ao contrário disso, sejam adotadas condutas "uniformes e compreensíveis" em prol do "bem comum", o autor entende ser necessário que nos tornemos responsáveis pela sociedade em que vivemos, adotando uma forma de consciência que seja sinônimo de inteligência "organizada", "eficaz" e "livre".

\section{O layout do argumento}

O argumento de Dewey (1997a) no ensaio "Intelligence and morals" pode ser formulado, resumidamente, como segue: os pensadores renascentistas e, principalmente, os modernos ofereceram importante contribuição para afastar a moral do domínio de fins absolutos, fixos e finais, superando, assim, a visão metafísica predominante até aquele momento. Embora essa meta não tenha sido plenamente realizada e certo pessimismo tenha surgido no século XIX, o legado da modernidade continua válido devido aos sensíveis avanços sociais obtidos desde então. Por isso, é possível que doravante ocorram profundas mudanças na atitude dos homens quanto ao valor da experiência, permitindo que a moral seja comandada pela inteligência, o que trará inegáveis benéficos para toda a sociedade.

No layout proposto por Toulmin (2001), conforme exposto na seção introdutória deste artigo, o Dado do argumento de Dewey pode ser expresso pelo seguinte enunciado: Os filósofos renascentistas e modernos afastaram a moral do domínio de objetivos fixos e a tornaram associada à inteligência. A Conclusão, por sua vez, pode ser assim escrita: No futuro, a moral provavelmente será regida pela inteligência. Essa última afirmação revela que o objetivo central de "Intelligence and morals" é estabelecer uma tese relativa não apenas ao presente, mas, principalmente, ao futuro. Considerando os 
parâmetros da análise retórica, pode-se dizer que o intuito do texto é mobilizar a audiência para aderir a uma expectativa otimista concernente ao que está por vir.

O que permite passar do Dado à Conclusão é a narrativa de que os avanços propiciados pelo renascimento e pela modernidade ainda se mantêm ativos e, portanto, capazes de conferir a configuração desejada aos problemas morais. Sendo assim, a Garantia do argumento pode ser assim redigida: As filosofias renascentista e moderna propiciaram avanços duradouros. Trata-se, obviamente, de uma afirmação que pode ou não ser aceita pela audiência, como são, aliás, todas as afirmações caracterizadas por Toulmin (2001) como responsáveis por sustentar a passagem de um Dado a uma Conclusão. É por esse motivo que Dewey se empenha em persuadir seus leitores acerca dos supostos avanços ocorridos desde que os renascentistas e os modernos vincularam a moral à inteligência.

Tais explicações constituem o que, no layout de Toulmin (2001), denomina-se Apoio da Garantia. Para Dewey (1997a), a vinculação da moral à inteligência resultou em uma ciência livre e progressista, visto que, anteriormente, a ciência era, de algum modo, vinculada às problemáticas da moral. O desenvolvimento científico foi requisito fundamental para a efetivação do movimento industrial ocorrido a partir da modernidade. Esse movimento, por sua vez, viabilizou a democracia, e ambos foram responsáveis pelas profundas mudanças instauradas na atitude dos homens quanto à busca por melhores condições de existência. Todo esse processo foi tributário da substituição do costume fixo por uma nova concepção acerca das relações entre os homens, a qual permitiu melhorias em todos os setores da vida social.

O layout do argumento de Dewey pode ser formalizado conforme o Quadro 2.

Quadro 2- O layout do argumento de Dewey

(Dado) Os renascentistas e os modernos afastaram a moral do domínio de objetivos fixos e a tornaram associada à inteligência.
(Conclusão) Provavelmente, no futuro a moral será regida pela inteligência.

(Garantia) As filosofias renascentista e moderna propiciaram avanços duradouros no campo da moral. (Apoio) A vinculação da moral com a inteligência possibilitou o desenvolvimento científico e industrial, bem como a democracia.

Fonte: Elaborado pelos autores. 
Visto que a Conclusão só se torna persuasiva mediante a aceitação da Garantia, o Apoio argumentativo precisa mostrar-se resistente a possíveis Refutações. Um interlocutor interessado em combater a tese otimista de Dewey (1997a) deverá contrariar a afirmação de que os referidos avanços propiciados pela modernidade ainda se verificam e, mais ainda, que serão verificados no futuro. Poderá dizer, por exemplo, que a durabilidade dos tais avanços é ilusória, ou que tais progressos, embora duradouros, não foram ocasionados pelos desenvolvimentos filosóficos daquele período, sendo consequências de outros fatores.

A Garantia do argumento é abalada por qualquer uma dessas alegações refutatórias, especialmente pela primeira, cujo enunciado atinge diretamente a causa daquele otimismo. Em outras palavras, Dewey (1997a) acredita que a moral será regida pela inteligência por causa da durabilidade exibida pelos avanços propiciados por renascentistas e modernos; se for possível mostrar que essa durabilidade é falsa, cairão por terra os motivos da referida esperança.

O exame das teorias da moral a partir de sua origem, tal qual é feito por Dewey (1997a) no ensaio, é uma estratégia argumentativa que cumpre a função de antídoto a essa Refutação. Cunha e Sacramento (2007) dão o nome de recurso à origem a essa estratégia, cuja característica consiste em examinar o nascedouro de determinado problema e acompanhar o seu desenvolvimento com o propósito de conferir solidez ao discurso. A remissão à origem permite à audiência identificar de modo mais preciso o tema em pauta, bem como tornar mais compreensíveis os seus desdobramentos. Além disso, vincular fatos presentes a eventos do passado favorece o exame da questão na atualidade; alusões a ocorrências pretéritas dão credibilidade a quem pretenda indicar "lições para o futuro" (SILVA; CUNHA, 2011).

O recurso à origem é fundamental para estabelecer o Apoio da Garantia do argumento central de "Intelligence and morals". As explanações feitas por Dewey (1997a) acerca da história da filosofia, focalizando as relações entre inteligência e moral desde os primórdios da história do pensamento, visam desenhar uma linha de progressão que culmina na modernidade, firmando o caráter permanente das alegadas conquistas nessa área. Ao reconstituir, a seu modo, a trajetória da filosofia, o autor pretende mostrar que o pensar filosófico finalmente alcançou o seu ápice ao reconhecer que a interferência de instâncias metafísicas no terreno da moralidade ocasiona prejuízos à vida social. Assim, a inteligência torna-se o meio correto para deliberar sobre tais assuntos. 


\section{Considerações finais}

A análise do ensaio "Intelligence and morals" de John Dewey (1997a), tal qual realizada no presente artigo, permite observar que, para veicular suas concepções acerca do tema em pauta, o autor elabora uma narrativa da história da filosofia no tocante às teorias da moral. Seu intuito não é apontar equívocos conceituais ou lógicos no material examinado, mas discorrer sobre diversos pensadores utilizando um critério que diz respeito à capacidade das filosofias para responder às demandas concretas de suas respectivas épocas. Sua linha de raciocínio indica que o transcendentalismo vigente durante longo período, desde os gregos da Era Clássica ao término da Era Medieval, foi incapaz de realizar essa meta, pois não ofereceu sustentação às referidas demandas, inviabilizando o enfrentamento das contradições sociais, em que se incluem os problemas educacionais.

A narrativa de Dewey (1997a) sustenta que tal quadro de inoperância foi modificado quando os filósofos renascentistas, seguidos pelos modernos, conseguiram dissociar a moral da esfera metafísica, norteando suas reflexões pelo conceito de inteligência, inflexão esta que tornou possível o desenvolvimento científico, bem como o movimento industrial e o nascimento da democracia. Desse modo, o filósofo pavimenta o caminho para a aceitação da tese pragmatista, segundo a qual as questões morais devem ser norteadas pela inteligência, não por fins situados acima da experiência humana. Uma vez que os avanços obtidos desde o Renascimento ainda se encontram vivos, está assegurada a hegemonia da inteligência na esfera das reflexões morais, o que torna a filosofia habilitada a tomar parte na projeção de um futuro menos sombrio para a humanidade.

Conforme procuramos destacar aqui, essa argumentação é sustentada pela estratégia discursiva que denominamos recurso à origem, a qual consiste em traçar o histórico de um tema desde os primeiros indícios de seu surgimento, de maneira a exibir sua situação presente e indicar seu desenvolvimento futuro. No ensaio "Intelligence and morals" (DEWEY, 1997a), a história da filosofia é objeto dessa estratégia, resultando em uma narrativa genealógica que atende ao propósito de posicionar a moral no âmbito da vida social, marcada pela temporalidade e transitoriedade, em oposição à fixidez do plano metafísico. Trata-se de um discurso retórico por conter um intuito persuasivo cuja meta é criar na audiência uma disposição favorável à tese proposta.

Dewey faz uso frequente dessa estratégia em suas obras, com variados propósitos persuasivos. Cunha e Sacramento (2007) analisam que em Democracia e educação (DEWEY, 1959) o recurso à origem presta-se a estabelecer um vínculo indissociável entre a educação a vida política, razão pela 
qual seria impossível pensar a transformação educacional isoladamente dos fatores sociais. Para sustentar essa tese, o autor remete-se à origem da filosofia entre os gregos antigos, mostrando que a reflexão filosófica determinante das formas de educar daquele povo emergiu das problemáticas vividas por sua civilização, constituindo um produto das limitações de sua sociedade. Por não conseguirem superar os condicionantes de seu modo de vida, os gregos não foram capazes de ultrapassar as margens dualistas de sua filosofia e de seu sistema educacional.

Nesse livro, Dewey (1959) defende que a essência dos problemas gregos ainda se apresenta na atualidade, pois ainda permanece uma forma de educação que limita a poucos o acesso à formação intelectual, enquanto a maioria recebe somente uma instrução de caráter mecânico. A estratégia do recurso à origem, nesse caso, visa evidenciar a persistência da desigualdade na distribuição do conhecimento entre as classes sociais, e que a sua superação só ocorrerá, de fato, quando houver uma sociedade verdadeiramente democrática.

O recurso à origem é uma forma de argumentar bastante comum não apenas em John Dewey, mas também em outros autores contemporâneos, particularmente no campo da educação. Independentemente da filiação teórica do discurso, sua eficácia pode ser atribuída ao fato de proporcionar à audiência um quadro geral do tema examinado, posicionando em seu interior o ponto de vista do autor da narrativa acerca do objeto em questão. O que se pode indagar a partir dessas reflexões é sobre a fonte desse modo de argumentar. Seria a história - a história da filosofia, em particular - um recurso argumentativo comum entre pensadores de outras épocas? Seria possível identificar em que momento e a partir de qual filósofo a genealogia passou a constituir um meio eficaz de persuadir? Estas e outras perguntas poderão ser respondidas oportunamente, por meio de investigação específica.

\section{Notas}

${ }^{1}$ Dewey aposentou-se em Columbia em 1930, mas continuou produzindo até próximo da sua morte, deixando extensa obra sobre temáticas educacionais e assuntos próprios da filosofia, como a lógica, a política e a estética (AMARAL, 1990; CUNHA, 2011).

${ }^{2}$ No ensaio ora examinado, Dewey (1997a) define inteligência apenas indiretamente, em oposição ao que se firma pela tradição, de maneira acrítica. Em obras posteriores - Como pensamos (DEWEY, 1953) e Democracia e educação (DEWEY, 1959), por exemplo -, o conceito é associado ao "pensamento reflexivo", processo que consiste em solucionar situações problemáticas por meio da investigação. 


\section{REFERÊNCIAS}

AMARAL, Maria Nazaré C. P. Dewey: filosofia e experiência democrática. São Paulo: Perspectiva, 1990.

CUNHA, Marcus Vinicius. História da Educação e Retórica: ethos e pathos como meios de prova. In: SILVA, Marilda; VALDEMARIN, Vera Teresa (Org.). Pesquisa em educação: métodos e modos de fazer. São Paulo: Cultura Acadêmica, 2010. p. 11-46.

CUNHA, Marcus Vinicius. John Dewey: uma filosofia para educadores em sala de aula. 6. ed. Petrópolis, RJ: Vozes, 2011.

CUNHA, Marcus Vinicius; CARVALHO, Daniele Cristine. Um orador e seu auditório: análise retórica do discurso de John Dewey sobre o darwinismo. Educação e Cultura Contemporânea, Rio de Janeiro, v. 8, n. 17, jul./dez. 2011.

CUNHA, Marcus Vinicius; SACRAMENTO, Leonardo Freitas. Os gregos nas estratégias argumentativas de John Dewey. Revista Brasileira de Educação, Campinas, SP, v. 12, n. 35, p. 278289, maio/ago. 2007.

DEWEY, John. Intelligence and morals. In: DEWEY, John. The influence of darwinism on philosophy and others essays. New York: Prometheus Books, 1997a. p. 46-76.

DEWEY, John. The influence of darwinism on philosophy. In: DEWEY, John. The influence of darwinism on philosophy and other essays. New York: Prometheus Book, 1997b. p. 1-19.

DEWEY, John. The philosophical work of Herbert Spencer. In: DEWEY, John. The middle works of John Dewey, 1899-1924 - v. 3: 1903-1906. 2. ed. Carbondale: Southern Illinois University, 1997c. p. 194-210.

DEWEY, John. A criança e o programa escolar. In: DEWEY, John. Vida e educação. Tradução de Anísio Teixeira. 10. ed. Rio de Janeiro: Melhoramentos, 1978a. p. 42-61.

DEWEY, John. Interesse e esforço. In: DEWEY, John. Vida e educação. Tradução Anísio Teixeira. 10. ed. Rio de Janeiro: Melhoramentos, 1978b. p. 62-112.

DEWEY, John. Como pensamos. 2. ed. Tradução de Godofredo Rangel. São Paulo: Nacional, 1953.

DEWEY, John. Democracia e educação: introdução à filosofia da educação. Tradução de Godofredo Rangel e Anísio Teixeira. 3. ed. São Paulo: Nacional, 1959.

DEWEY, John. Experiência e educação. Tradução de Anísio Teixeira. São Paulo: Nacional, 1971.

GARRISON, Jim. The "permanent deposit" of Hegelian thought in Dewey's theory of inquiry. Educational Theory, Malden, v. 56, n. 1, p. 1-37, 2006. 
HAHN, Lewis E. Introduction. In: DEWEY, John. The middle works: 1899-1924. 2. ed. Carbondale: Southern Illinois University, 2008. v. 4.

MOREIRA, Carlos Otávio Fiúza. Entre o indivíduo e a sociedade: um estudo da filosofia da educação de John Dewey. Bragança Paulista, SP: Universidade São Francisco, 2002.

CARVALHO, Daniele Cristine; SILVA, Tatiane; CUNHA, Marcus Vinicius. A metáfora fundamental do discurso de John Dewey. Educação e Cultura Contemporânea. Rio de Janeiro, v. 11, n. 24, p. 142$162,2014$.

PERELMAN, Chaïm; OLBRECHTS-TYTECA, Lucie. Tratado da argumentação: a nova retórica. Tradução de Maria E. Galvão. São Paulo: Martins Fontes, 2002.

SILVA, Tatiane; CUNHA, Marcus Vinicius. Análise retórica da Pedagogia do Estado Novo. Educação e Cultura Contemporânea, Rio de Janeiro, v. 8, n. 16, jan./jun. 2011.

TOULMIN, Stephen. Os usos do argumento. Tradução de Reinaldo Guarany. São Paulo: Martins Fontes, 2001.

VALDEMARIN, Vera Teresa. História dos métodos e materiais de ensino: a escola nova e seus modos de uso. São Paulo: Cortez, 2010. 


\section{History of Philosophy in John Dewey's discourse on morals}

\begin{abstract}
This article follows Chaïm Perelman and Stephen Toulmin's theoretical and methodological guidelines which foundations are found in the contemporary revision movement of Aristotle's philosophy. It aims at performing the rhetorical analysis of the essay "Intelligence and Morals" by John Dewey, published in 1908, in which the author advances the thesis that since Renaissance moral has become unrelated of transcendental ends, being hence based on intelligence. The exam of the essay reveals the use of the discursive strategy called "recourse to origin", which consists of elaborating a genealogical narrative about the history of philosophy in order to sustain the author's thesis. This article suggests that this form of reasoning is frequently found in Dewey's work: it can also be observed in the book Democracy and education, in which the philosopher discourses about history of philosophy to show that philosophical reflection on education emerges from social problems.
\end{abstract}

Keywords: Dewey, John. Rhetoric. Philosophy and Education.

\section{L'histoire de la philosophie chez le discours de John Dewey sur la morale}

\section{Résumé}

Cet article suit des lignes directrices théoriques et méthodologiques originaires de Chaïm Perelman et Stephen Toulmin, dont les fondements sont trouvés chez le mouvement contemporain de révision de la philosophie d'Aristote. Son but consiste dans l'analyse rhétorique de l'essai "Intelligence and Morals" ["Intelligence et morale"] de John Dewey, publié à 1908 , où l'auteur défend la thèse selon laquelle depuis la Renaissance la morale est devenue detachée des fins transcendantales, s'étant donc basée sur l'intelligence. L'examen de l'essai révèle l'utilisation d'une stratégie discursive nommée "recours à l'origine", qui consiste dans l'élaboration d'une narration généalogique concernant l'histoire de la philosophie, à fin de soutenir la thèse de l'auteur. Cet article suggère que cette forme d'argumentation est fréquente chez Dewey, comme on peut aussi observer au livre Democracy and education [Démocratie et éducation], dont le philosophe discourt sur l'histoire de la philosophie pour montrer que la réflexion philosophique sur l'éducation émerge de questions sociales.

Mots-clés: John Dewey. Rhétorique. Philosophie et Éducation.

Enviado em: 28/5/2015

Aprovado em: 23/7/2015

\section{Marcus Vinicius da Cunha}

E-mail: mvcunha2@hotmail.com

Paulo Fernando Aleixo da Cruz

E-mail: fernandoac@hotmail.com 